\title{
Psychometric properties and assessment of the Osteoporosis Health Belief Scale among the general Arabic population
}

This article was published in the following Dove Press journal:

Patient Preference and Adherence

\author{
Mohanad Naji Sahib \\ Faculty of Pharmacy, Al-Rafidain \\ University College, Baghdad, Iraq
}

Correspondence: Mohanad Naji Sahib Faculty of Pharmacy, Al-Rafidain University College, Palestine Street, Baghdad 10052, Iraq

Emailmohanad_pharm@yahoo.com
Background: Any educational program should be implemented with a good understanding of the population's beliefs. Therefore, the aims of this study were to validate the Arabic version of the Osteoporosis Health Belief Scale (OHBS-A) and assess the osteoprotective attitude among the Iraqi population.

Methods: A cross-sectional design, with a random cluster sampling method from the community, was used. The forward-backward-forward translation method was used to translate the questionnaire from English to Arabic. In addition, the Arabic version of Osteoporosis Knowledge Tool (OKT-A) and the Arabic version of Osteoporosis Self-Efficacy Scale (OSES-A) were used to assess the osteoprotective behaviors.

Results: The results showed good face validity and reliability. The construct validity analysis showed seven factors that explain $72.82 \%$ of the variance. In addition, the results revealed a low health belief score (149.95 \pm 35.936$)$ with only $36.67 \%$ of the study population found to have a high OHBS-A level. The results showed significant differences among employment status, marital status, and osteoporosis (OP) awareness groups in relation to total OHBS-A scores. In addition, there were significant associations between age groups and OP awareness with health belief levels. Moreover, both exercise and calcium intake subscales of the Osteoporosis Knowledge Tool (OKT) positively correlated with all OHBS-A subscales. Exercise and calcium intake subscales of Osteoporosis Self-Efficacy Scale (OSES) positively correlated with the perceived susceptibility and perceived barriers toward exercise and calcium intake. The binary logistic regression analysis showed that OKT levels, OSES levels, and age were predictors of OHBS-A levels.

Conclusion: Besides cultural obstacles, an educational program for both genders and all age groups is important and should be tailored according to culture needs.

Keywords: health belief, osteoporosis, osteoprotective behavior

\section{Introduction}

Osteoporosis (OP) is a skeletal disorder characterized by low bone quality and strength as a consequence of decreasing bone mineral density. This will lead to increased susceptibility to fractures, especially among the elderly. ${ }^{1-4}$ The optimum peak bone mass during younger age is an important factor that confers the ability to withstand bone resorption that occurs in advanced age. ${ }^{5} \mathrm{OP}$ is difficult to treat; however, evidence shows that a healthy lifestyle can prevent its development. ${ }^{6}$ Hence, OP can be especially slowed or delayed with behavioral risk factor modification such as increasing dietary calcium and vitamin D, exercising suitably, and stopping smoking and alcohol consumption. ${ }^{7,8}$ 
The OP health belief plays a central role in OP prevention and behavior management. Osteoporosis Health Belief Scale (OHBS) is developed based on the health belief model (HBM) theory, ${ }^{9}$ which proposes that individual prevention behaviors increase, if patients feel susceptible, believe that the occurrence of disease would have a severe impact on their lives, and conclude that preventive measures are beneficial, outweighing any limitations involved in taking action. ${ }^{10,11}$ The major obstacles that were identified in the management of OP included a limited level of awareness and knowledge within the population. ${ }^{12,13}$ Moreover, the self-efficacy building process includes an interaction between emotional states, motivation, and outcome expectancy. ${ }^{14}$ Therefore, self-efficacy contributes to motivation by helping people determine their goals, how much effort they expend, how long they persevere in the face of difficulty, and their resilience to failures.

Although knowledge is crucial for healthy life style behaviors, it is not solely enough for changing behavior. ${ }^{15-18}$ Health care professionals can develop and implement a specific educational program according to good understanding of populations' belief and self-efficacy as changing lifestyle and health behaviors at an early age will have a greater impact on the prevalence of OP. ${ }^{19-22}$

Therefore, the aims of this study were to validate the Arabic version of the Osteoporosis Health Belief Scale (OHBS-A) and assess osteoprotective behaviors among the Iraqi population as a first step for future implementation of the OP prevention program.

\section{Methods}

\section{Participants and study design}

A community-based, cross-sectional study was conducted from November 2016 to February 2017 in Baghdad, Iraq. Baghdad city has two large areas named Al-Karkh (west of the Tigris; four districts) and Al-Rusafa (east of the Tigris; six districts). A random cluster sampling method was used to select three districts from these areas. Then, systematic samples were randomly selected from the community pharmacies where the undergraduate students underwent training in these districts. Equal numbers of participants were recruited from each district. The inclusion criteria for participants were as follows: $>18$ years, no cognitive impairment, and able to read and write Arabic. A structured interview included collection of the sociodemographic and translated OHBS-A data. Each participant was interviewed individually by the researcher or trained fifth-year undergraduate student after obtaining written and/or verbal informed consent. Owing to differences in extent of education and cultural obstacles, some of the participants refused to sign the consent form, because they considered it impolite behavior given that they had already given verbal consent for participation. Therefore, only verbal informed consent was obtained from them. Approval of study protocol and ethical approval (including verbal informed consent) were obtained from the scientific committee of Al-Rafidain University College, Baghdad, Iraq.

\section{Sample size}

As per recommendation, at least five subjects per item are needed to evaluate the reliability and validity of a questionnaire. ${ }^{23}$ The original OHBS consists of 42 questions; therefore, 210 participants were needed for validation purpose. However, for factor analysis, it is preferable to use 300 subjects. $^{24}$ Therefore, doubling the sample size, with an additional $10 \%$ as dropout, was considered necessary to overcome reporting error and increase the reliability of results. Moreover, with this number of participants, it would be possible to discriminate between high and low correlations in measuring correlations. ${ }^{25}$ While 400 participants were initially found eligible for inclusion, 75 had to be excluded owing to incomplete responses. Therefore, only 325 participants were selected for this study. In all, 25 participants from the sample population were randomly selected for test-retest within 1-2 weeks.

\section{Instruments and measurements}

All participants completed the structured questionnaires including the OHBS-A. The original OHBS is in the English language and designed to assess health beliefs about developing OP., 9,26 The OHBS consists of 42 Likerttype scales ( $1=$ strongly disagree and $5=$ strongly agree) and seven subscale items: perceived susceptibility, perceived seriousness, perceived benefits of exercise, perceived benefits of calcium intake, perceived barriers to exercise, perceived barriers to calcium intake, and health motivation. The total possible score ranges from 42 to 210 with each subscale range score from 6 to 30. A cutoff point (169) was used to categorize the OP health belief scores into two levels: low and high OHBS-A. ${ }^{27}$

Beside OHBS-A, unpublished but valid and reliable Arabic version of Osteoporosis Knowledge Tool (OKT-A) and Arabic version of Osteoporosis Self-Efficacy Scale (OSES-A) were administered before and after OHBS-A, respectively, according to the developer's instructions. The original Osteoporosis Knowledge Tool (OKT) and OSES are formulated in English and designed to assess OP 
knowledge and self-efficacy of behaviors, respectively. ${ }^{26,28}$ The OKT comprises 24 multiple-choice items regarding risk factors and its prevention. It is divided into two parts: OKT-exercise subscale and OKT-calcium subscale. The possible score range is $0-24$, and the highest value indicates the highest level of knowledge score. The OSES is a 12-item scale rated by an individual on a $100-\mathrm{mm}$ visual analog scale to assess the confidence in practicing OP-preventive behaviors. The OSES has two subscales, namely, the exercise and calcium. The range of possible total score is $0-1,200$ with each subscale score ranging between 0 and 600 .

\section{Instrument translation and face validity}

The forward-backward-forward translation method was used to translate the questionnaire from English to Arabic according to translation international guidelines including forward translation, reconciliation, reverse translation, and debriefing. ${ }^{29-31}$ The translation process was undertaken by two independent, expert translators in Iraq. Then, an expert panel of eight clinical pharmacists and the researcher reviewed the Arabic version for reconciliation. Subsequently, back translation of the reconciled version was carried out by two different translators. Thereafter, repeated discussions between the translators, expert panel, and the researcher were held to resolve any inconsistencies, and the final version was decided as the face validity process. ${ }^{32}$

Finally, a pilot study was conducted by distributing the questionnaire to 30 participants from the same demographic area in Baghdad, and the questionnaire was modified according to their feedback. These 30 participants were excluded from the final study outcome and analysis.

\section{Construct validity}

Exploratory factor analysis (EFA) was carried out to examine the factor structures of OHBS-A. A principal axis factoring method for extraction with varimax rotations was used for EFA. The criteria for EFA were factor loading $>0.40$, KaiserMeyer-Olkin (KMO) value $>0.5$, and significant level of Bartlett's test of sphericity $<0.05$. The number of factors to retain was dependent on Kaiser's criterion (eigenvalue $\geq 1.0$ ) and theoretical meaning of the rotated factors. ${ }^{33}$

\section{Reliability}

Reliability with a minimum acceptable criterion $>0.5$ was applied to measure the consistency of a measurement item. ${ }^{34}$ The internal consistency was evaluated using Cronbach's alpha and corrected item - total correlation values between the scales and their corresponding items (correlation of $<0.20$ was considered as poor). Pearson's correlation coefficient was used to evaluate test-retest reliability. ${ }^{23}$

\section{Statistical analysis}

Predictive analytics software (PASW) version 19.0 was used to analyze data in this study. The significance level was set at $P$-value $<0.05$. Descriptive statistics, percentages, and frequencies were used as appropriate. The chi-square $\left(\chi^{2}\right)$ test was used for categorical variables, whereas for continuous data, Mann-Whitney $U$ and Kruskal-Wallis tests were used to evaluate the differences between the groups when required. The statistical analysis of the validation processes included assessing construct validity and reliability (Cronbach's alpha and test-retest). In addition, logistic regression analysis using the backward method was used to identify the factors affecting OHBS-A.

\section{Results Sociodemographic factors}

The mean age of the participants was $41.82 \pm 12.452$ years (range, $18-87$ years). Nearly $46 \%$ of respondents were male. Approximately $21 \%$ of the respondents had educational level $<12$ years. Approximately $77 \%$ of the respondents were not single (including married, widowed, and divorced), and $\sim 62 \%$ had a monthly income of $>500,000$ Iraqi Dinar (IQD; 1 US dollar is equivalent to 1,250 IQD). By using the recommended scoring method, the scores of mean $(\mathrm{M}) \pm \mathrm{SD}$ of the OHBS-A were 149.95 \pm 35.936 , which are considered as low scores.

Table 1 gives the distribution of the two levels of OP health belief and the demographic data. Only $36.67 \%$ of the study population was found to have a high OHBS-A level. The results showed significant difference between the following independent variables in relation to total OHBS-A scores: ever heard about OP, employment status, and marital status. In addition, there were significant association between age and ever heard about OP with OHBS-A belief levels (Table 1). Table 2 gives that moderate health belief in all dimensions (less than 77\%) with the lowest values appearing in the subscales of barriers (64\%).

\section{Validity}

Face validity

As a result of the extensive translation method and pilot testing, qualitative face validity was guaranteed.

\section{EFA}

In this study, a principal axis factoring analysis method was conducted on the 42 items with orthogonal rotation (varimax). 
Table I Demographic characteristics of participants

\begin{tabular}{|c|c|c|c|}
\hline Characteristics & $\begin{array}{l}\text { Total samples } \\
(\mathrm{N}=\mathbf{3 0 0})\end{array}$ & $\begin{array}{l}\text { Low health belief } \\
(n=190)\end{array}$ & $\begin{array}{l}\text { High health belief } \\
(n=I \mid 0)\end{array}$ \\
\hline 42-item OHBS-A score & $149.95 \pm 35.936$ & $131.44 \pm 32.795$ & $181.94 \pm 6.902$ \\
\hline Perceived susceptibility for OP & $20.68 \pm 5.594$ & $18.47 \pm 5.387$ & $24.49 \pm 3.513$ \\
\hline Perceived seriousness for OP & $22.37 \pm 5.990$ & $20.26 \pm 6.333$ & $26.00 \pm 2.799$ \\
\hline Perceived benefits of exercise & $22.81 \pm 6.385$ & $21.13 \pm 7.072$ & $25.70 \pm 3.434$ \\
\hline Perceived benefits of calcium & $22.34 \pm 6.016$ & $20.17 \pm 6.234$ & $26.08 \pm 3.095$ \\
\hline Perceived barriers to exercise & $19.43 \pm 8.257$ & $14.67 \pm 6.343$ & $27.66 \pm 3.051$ \\
\hline Perceived barriers to calcium & $19.33 \pm 7.928$ & $15.35 \pm 6.191$ & $26.22 \pm 5.515$ \\
\hline Health motivation & $23.00 \pm 6.174$ & $21.38 \pm 6.932$ & $25.78 \pm 2.978$ \\
\hline \multicolumn{4}{|l|}{ Age* (years) } \\
\hline$\leq 44$ & 59.7 & 54.2 & 69.1 \\
\hline$\geq 45$ & 40.3 & 45.8 & 30.9 \\
\hline \multicolumn{4}{|l|}{ Gender } \\
\hline Male & 46 & 46.3 & 45.5 \\
\hline Female & 54 & 53.7 & 54.5 \\
\hline \multicolumn{4}{|l|}{ Educational level (years) } \\
\hline$<12$ & 21 & 24.2 & 15.5 \\
\hline$\geq 12$ & 79 & 75.8 & 84.5 \\
\hline \multicolumn{4}{|l|}{ Marital status** } \\
\hline Single & 23 & 20 & 28.2 \\
\hline Not single & 77 & 80 & 71.8 \\
\hline \multicolumn{4}{|l|}{ Employment status** } \\
\hline Working & 84 & 85.3 & 81.8 \\
\hline Not working & 16 & 14.7 & 18.2 \\
\hline \multicolumn{4}{|l|}{ Monthly income (IQD) } \\
\hline$\leq 500,000$ & 38 & 36.8 & 40 \\
\hline$>500,000$ & 62 & 63.2 & 60 \\
\hline \multicolumn{4}{|l|}{ Living place } \\
\hline Rural & 22 & 21.1 & 23.6 \\
\hline Urban & 78 & 78.9 & 76.4 \\
\hline \multicolumn{4}{|l|}{ Family history of OP } \\
\hline No & 72.7 & 71.1 & 75.5 \\
\hline Yes & 27.3 & 28.9 & 24.5 \\
\hline \multicolumn{4}{|l|}{ Family history of fracture } \\
\hline No & 59 & 55.8 & 64.5 \\
\hline Yes & 41 & 44.2 & 35.5 \\
\hline \multicolumn{4}{|l|}{ Do you have OP } \\
\hline No & 89.3 & 87.4 & 92.7 \\
\hline Yes & 10.7 & 12.6 & 7.3 \\
\hline \multicolumn{4}{|l|}{ Do you have fracture before* } \\
\hline No & 82 & 80 & 85.5 \\
\hline Yes & 18 & 20 & 14.5 \\
\hline \multicolumn{4}{|l|}{ Ever heard about OP**** } \\
\hline No & 7 & 9.5 & 2.7 \\
\hline Yes & 93 & 90.5 & 97.3 \\
\hline \multicolumn{4}{|l|}{ OP diagnosis or screening } \\
\hline No diagnosis before & 82 & 81.6 & 82.7 \\
\hline Yes & 18 & 18.4 & 17.3 \\
\hline \multicolumn{4}{|l|}{ Smoking habit } \\
\hline Not smoking & 79.3 & 78.9 & 80 \\
\hline Smoking & 20.7 & 21.1 & 20 \\
\hline \multicolumn{4}{|l|}{ Alcohol habit } \\
\hline Nonalcoholic & 99.3 & 98.9 & 100 \\
\hline Alcoholic & 0.7 & 1.1 & 0.0 \\
\hline
\end{tabular}

Notes: Data are expressed as mean \pm SD or frequency (\%). $*$ Significant association between groups, $P<0.05$. **Significant difference, $P<0.05$.

Abbreviations: IQD, Iraqi dinar (I US dollar is equivalent to I,250 IQD); OHBS-A, Arabic version of the Osteoporosis Health Belief Scale; OP, osteoporosis. 
Table 2 Description of OHBS-A subscale $(\mathrm{N}=300)$

\begin{tabular}{llll}
\hline Construct & Mean \pm SD (median) & Potential range & Belief (\%) \\
\hline Perceived susceptibility & $20.68 \pm 5.594(21)$ & $6-30$ & 68.93 \\
Perceived seriousness & $22.37 \pm 5.990(24)$ & $6-30$ & 74.57 \\
Perceived benefits of exercise & $22.81 \pm 6.385(25)$ & $6-30$ & 76.03 \\
Perceived benefits of calcium intake & $22.34 \pm 6.016(24)$ & $6-30$ & 74.47 \\
Perceived barriers to exercise & $19.43 \pm 8.257(19)$ & $6-30$ & 64.77 \\
Perceived barriers to calcium intake & $19.33 \pm 7.928(18)$ & $6-30$ & 64.43 \\
Health motivation & $23.00 \pm 6.174(25)$ & $6-30$ & 76.67 \\
Total OHBS-A & $149.95 \pm 35.936(155.50)$ & $42-210$ & 71.40 \\
\hline
\end{tabular}

Abbreviation: OHBS-A, Arabic version of the Osteoporosis Health Belief Scale.

Upon examination of the correlation matrices, a majority of the results showed a correlation $>0.3$. The KMO value was 0.954, which indicated that the data set was appropriate for EFA as it was $>0.5 . .^{33}$ The last measure was the Bartlett's test of sphericity, which was found to be highly significant, $\chi^{2}(861)=10,940.292 ; P<0.001$. These results allowed us to identify a factor model using the EFA approach. ${ }^{35,36}$ In addition, the analysis revealed seven factors with eigenvalues $>1$, which explained $72.82 \%$ of the variance, as given in Table 3 . The entire results showed adequacy for factor analysis and seven domain (subscales) variables.

\section{Reliability}

For reliability testing, the Cronbach's alpha test of internal consistency was 0.962 for the 42 items in OHBS-A, which was within the recommended acceptable result for reliability. ${ }^{34}$ The test-retest reliability of 42 items in OHBS-A indicated an excellent reliability and stability of the instrument with Pearson's correlation coefficient ( $r=0.869, P<0.001)$. An initial Cronbach's alpha result for the OHBS-A test-retest group was 0.854 , and after $1-2$ weeks, it was 0.687 . These results demonstrated that OHBS-A was reliable and stable. The corrected item - total correlation values, which were the reliability index values, ranged from 0.278 to 0.757 (Table 4). All items appeared suitable for retention depending on the meaningfulness of the items. ${ }^{23}$

\section{Multivariate and correlation analyses}

Correlations were performed to determine the relationship between OKT-A and OSES-A subscales with total OHBS-A and its subscales (Table 5). Both OKT-A exercise and calcium intake subscales were positively correlated with all OHBS-A subscales. OSES-A exercise and calcium intake subscales were positively correlated with the perceived susceptibility, perceived barriers to exercise, and perceived barriers to calcium intake. In addition, the total OHBS-A score was correlated with total OKT-A $(r=0.409)$ and total OSES-A $(r=0.238$; all $P<0.01)$. Moreover, total OKT-A score was positively correlated with the perceived susceptibility $(r=0.312)$ and perceived seriousness $(r=0.306$; all $P<0.01)$. However, total OSES-A score was positively correlated with the perceived susceptibility only $(r=0.167, P<0.01)$. The binary logistic regression revealed that OKT-A (categorical), OSES-A (categorical), and age (categorical) were predictors for OHBS-A levels (Table 6), and the model explains $\sim 68 \%$ of the dependent variable.

\section{Discussion}

The most important role of any health care professional is to educate patients or the general population at risk regarding ways to improve their healthy behavior. Moreover, before any educational program is to be implemented, knowledge, health belief, and self-efficacy must be assessed so that the program could be tailored according to the population's needs. Therefore, to evaluate these educational efforts, valid and reliable scales must be available. This study showed that the OHBS-A tool in conjunction with OKT-A and OSES-A can be successfully implemented to assess osteoprotective behaviors among the general population and used in clinical settings as well.

The face validity was carefully reviewed and revised by a panel of eight experts in the field of pharmacy. The EFA of the OHBS-A has a stable factor structure with seven domains related to health belief subscales that accounted for $72.82 \%$ of the variance, which was higher than that of other studies. ${ }^{9,37}$ The reliability of the OHBS-A, which is the consistency of a measurement item, was excellent with overall Cronbach's alpha being 0.962 . This value was higher than the original developed OHBS but comparable to that of Malaysian and Persian studies. ${ }^{9,27,37}$ This difference was likely because of differences in the population setting. The test-retest reliability showed good results that could be used 
Table 3 EFA for OHBS-A

\begin{tabular}{|c|c|c|c|c|c|c|c|c|}
\hline \multirow[t]{2}{*}{ Item } & \multicolumn{7}{|c|}{ Rotated factor matrix } & \multirow[t]{2}{*}{ Communalities } \\
\hline & Factor I & Factor 2 & Factor 3 & Factor 4 & Factor 5 & Factor 6 & Factor 7 & \\
\hline Question I & 0.519 & & & & & & & 0.563 \\
\hline Question 2 & 0.735 & & & & & & & 0.694 \\
\hline Question 3 & 0.837 & & & & & & & 0.802 \\
\hline Question 4 & 0.845 & & & & & & & 0.825 \\
\hline Question 5 & $0.78 I$ & & & & & & & 0.734 \\
\hline Question 6 & $0.58 I$ & & & & & & & 0.601 \\
\hline Question 7 & & 0.608 & & & & & & 0.676 \\
\hline Question 8 & & 0.565 & & & & & & 0.619 \\
\hline Question 9 & & 0.715 & & & & & & 0.782 \\
\hline Question 10 & & 0.582 & & & & & & 0.624 \\
\hline Question II & & 0.708 & & & & & & 0.773 \\
\hline Question 12 & & 0.569 & & & & & & 0.651 \\
\hline Question 13 & & & 0.774 & & & & & 0.758 \\
\hline Question 14 & & & 0.708 & & & & & 0.730 \\
\hline Question 15 & & & 0.754 & & & & & 0.786 \\
\hline Question 16 & & & 0.799 & & & & & 0.831 \\
\hline Question 17 & & & 0.806 & & & & & 0.787 \\
\hline Question 18 & & & 0.701 & & & & & 0.742 \\
\hline Question 19 & & & & 0.714 & & & & 0.813 \\
\hline Question 20 & & & & 0.72 & & & & 0.830 \\
\hline Question 21 & & & & 0.752 & & & & 0.801 \\
\hline Question 22 & & & & 0.726 & & & & $0.78 \mathrm{I}$ \\
\hline Question 23 & & & & 0.693 & & & & 0.749 \\
\hline Question 24 & & & & 0.717 & & & & 0.754 \\
\hline Question 25 & & & & & 0.769 & & & 0.757 \\
\hline Question 26 & & & & & 0.767 & & & $0.78 I$ \\
\hline Question 27 & & & & & 0.701 & & & 0.712 \\
\hline Question 28 & & & & & 0.803 & & & 0.797 \\
\hline Question 29 & & & & & 0.818 & & & 0.820 \\
\hline Question 30 & & & & & 0.819 & & & 0.796 \\
\hline Question 31 & & & & & & 0.61 & & 0.583 \\
\hline Question 32 & & & & & & 0.796 & & 0.783 \\
\hline Question 33 & & & & & & 0.535 & & 0.320 \\
\hline Question 34 & & & & & & 0.867 & & 0.870 \\
\hline Question 35 & & & & & & $0.85 I$ & & 0.835 \\
\hline Question 36 & & & & & & 0.586 & & 0.480 \\
\hline Question 37 & & & & & & & 0.615 & 0.639 \\
\hline Question 38 & & & & & & & 0.589 & 0.693 \\
\hline Question 39 & & & & & & & 0.683 & 0.782 \\
\hline Question 40 & & & & & & & 0.678 & 0.633 \\
\hline Question 4I & & & & & & & 0.759 & 0.786 \\
\hline Question 42 & & & & & & & 0.767 & 0.813 \\
\hline Eigenvalues & 4.013 & 3.565 & 5.126 & 4.614 & 4.938 & 4.16 & 4.167 & \\
\hline$\%$ of variance & 9.555 & 8.488 & 12.206 & 10.987 & 11.756 & 9.905 & 9.92 & Total $=72.82 \%$ \\
\hline Cronbach's $\alpha$ & 0.888 & 0.899 & 0.938 & 0.945 & 0.939 & 0.802 & 0.914 & Total $=0.962$ \\
\hline
\end{tabular}

Notes: Extraction method: principal axis factoring. Rotation method: varimax with Kaiser normalization. Factor I, OHBS-A susceptibility; Factor 2, OHBS-A seriousness; Factor 3, OHBS-A benefits of exercise; Factor 4, OHBS-A benefits of calcium intake; Factor 5, OHBS-A barriers to exercise; Factor 6, OHBS-A barriers to calcium intake; and Factor 7, OHBS-A health motivation. Items comprising each factor are in bold.

Abbreviations: EFA, exploratory factor analysis; OHBS-A, Arabic version of the Osteoporosis Health Belief Scale.

in longitudinal studies. For the test-retest group, the Cronbach's alpha value was lower than the initial value, indicating that the respondents may need a continuing educational program. This will increase their awareness about OP and, consequently, improve the outcome. The validity and reliability results revealed successful cultural adaptation.
This study showed low total scores for health belief. This result was comparable to other studies. ${ }^{21,38,39}$ After controlling OKT-A (two groups, means high and low knowledge), both age groups with low knowledge score were highly affected by the belief score toward OP, and the age group $\geq 45$ years had lower belief score. This is an important result as it showed 
Table 4 Reliability test of OHBS-A

\begin{tabular}{|c|c|c|c|c|}
\hline $\begin{array}{l}\text { Question } \\
\text { number }\end{array}$ & Mean & SD & $\begin{array}{l}\text { Corrected } \\
\text { item - total } \\
\text { correlation }\end{array}$ & $\begin{array}{l}\text { Cronbach's } \\
\text { alpha if item } \\
\text { deleted }\end{array}$ \\
\hline Question I & 3.59 & 1.151 & 0.619 & 0.961 \\
\hline Question 2 & 3.37 & 1.085 & 0.586 & 0.961 \\
\hline Question 3 & 3.40 & 1.050 & 0.532 & 0.962 \\
\hline Question 4 & 3.50 & 1.077 & 0.565 & 0.961 \\
\hline Question 5 & 3.40 & 1.188 & 0.547 & 0.962 \\
\hline Question 6 & 3.43 & 1.397 & 0.588 & 0.961 \\
\hline Question 7 & 3.81 & 1.378 & 0.683 & 0.961 \\
\hline Question 8 & 3.64 & 1.149 & 0.629 & 0.961 \\
\hline Question 9 & 3.74 & 1.171 & 0.692 & 0.961 \\
\hline Question 10 & 3.72 & 1.180 & 0.634 & 0.961 \\
\hline Question II & 3.69 & 1.245 & 0.666 & 0.961 \\
\hline Question 12 & 3.76 & 1.206 & 0.620 & 0.961 \\
\hline Question 13 & 3.79 & 1.247 & 0.618 & 0.961 \\
\hline Question 14 & 3.77 & 1.116 & 0.649 & 0.961 \\
\hline Question 15 & 3.84 & 1.235 & 0.670 & 0.961 \\
\hline Question 16 & 3.84 & 1.197 & 0.664 & 0.961 \\
\hline Question 17 & 3.73 & 1.209 & 0.618 & 0.961 \\
\hline Question 18 & 3.83 & 1.296 & 0.685 & 0.961 \\
\hline Question 19 & 3.82 & 1.138 & 0.757 & 0.961 \\
\hline Question 20 & 3.83 & 1.118 & 0.753 & 0.961 \\
\hline Question 2I & 3.68 & 1.111 & 0.718 & 0.961 \\
\hline Question 22 & 3.62 & 1.146 & 0.724 & 0.961 \\
\hline Question 23 & 3.66 & 1.184 & 0.727 & 0.961 \\
\hline Question 24 & 3.72 & 1.089 & 0.705 & 0.961 \\
\hline Question 25 & 3.33 & 1.615 & 0.647 & 0.961 \\
\hline Question 26 & 3.22 & 1.646 & 0.683 & 0.961 \\
\hline Question 27 & 3.19 & 1.590 & 0.675 & 0.961 \\
\hline Question 28 & 3.27 & 1.536 & 0.655 & 0.961 \\
\hline Question 29 & 3.20 & $|.54|$ & 0.659 & 0.961 \\
\hline Question 30 & 3.22 & $1.50 \mid$ & 0.616 & 0.961 \\
\hline Question 31 & 3.45 & 1.407 & 0.614 & 0.961 \\
\hline Question 32 & 3.13 & 1.484 & 0.601 & 0.961 \\
\hline Question 33 & 3.27 & 3.201 & 0.278 & 0.968 \\
\hline Question 34 & 3.17 & 1.494 & 0.596 & 0.961 \\
\hline Question 35 & 3.14 & 1.470 & 0.567 & 0.961 \\
\hline Question 36 & 3.17 & 1.415 & 0.487 & 0.962 \\
\hline Question 37 & 3.69 & 1.109 & 0.651 & 0.961 \\
\hline Question 38 & 3.83 & 1.196 & 0.732 & 0.961 \\
\hline Question 39 & 4.08 & 1.307 & 0.669 & 0.961 \\
\hline Question 40 & 3.69 & 1.317 & 0.586 & 0.961 \\
\hline Question 4I & 3.80 & 1.224 & 0.654 & 0.961 \\
\hline Question 42 & 3.90 & 1.217 & 0.651 & 0.961 \\
\hline
\end{tabular}

Abbreviation: OHBS-A, Arabic version of the Osteoporosis Health Belief Scale.

that any educational program should be highly focused on a high-risk group. Nayak et al ${ }^{40}$ showed that health belief was higher in younger than older age groups. However, any program should take into account both age groups and genders. The above result was consistent with the significant difference between OHBS-A score and awareness of the sample population regarding OP $(93 \%$ heard about OP). An Iranian study showed that the awareness and health belief were significantly different with respect to preventive behaviors. ${ }^{41}$
Table 5 OHBS-A correlation matrix

\begin{tabular}{lllll}
\hline Construct & $\begin{array}{l}\text { OKT-A } \\
\text { exercise }\end{array}$ & $\begin{array}{l}\text { OKT-A } \\
\text { calcium }\end{array}$ & $\begin{array}{l}\text { OSES-A } \\
\text { exercise }\end{array}$ & $\begin{array}{l}\text { OSES-A } \\
\text { calcium }\end{array}$ \\
\hline $\begin{array}{l}\text { Perceived susceptibility } \\
\text { Perceived seriousness }\end{array}$ & $0.360^{\mathrm{a}}$ & $0.323^{\mathrm{a}}$ & $0.173^{\mathrm{a}}$ & $0.119^{\mathrm{b}}$ \\
$\begin{array}{l}\text { Perceived benefits of } \\
\text { exercise }\end{array}$ & $0.338^{\mathrm{a}}$ & $0.300^{\mathrm{a}}$ & 0.068 & 0.066 \\
$\begin{array}{l}\text { Perceived barriers } \\
\text { to exercise }\end{array}$ & $0.360^{\mathrm{a}}$ & $0.350^{\mathrm{a}}$ & 0.104 & -0.030 \\
$\begin{array}{l}\text { Perceived benefits } \\
\text { of calcium }\end{array}$ & $0.304^{\mathrm{a}}$ & $0.354^{\mathrm{a}}$ & 0.030 & $0.120^{\mathrm{b}}$ \\
$\begin{array}{l}\text { Perceived barriers } \\
\text { to calcium }\end{array}$ & $0.401^{\mathrm{a}}$ & $0.42 \mathrm{I}^{\mathrm{a}}$ & $0.203^{\mathrm{a}}$ & $0.138^{\mathrm{b}}$ \\
\begin{tabular}{l} 
Health motivation \\
\hline
\end{tabular} & $0.347^{\mathrm{a}}$ & $0.353^{\mathrm{a}}$ & 0.088 & 0.049 \\
\hline
\end{tabular}

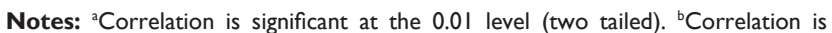
significant at the 0.05 level (two tailed).

Abbreviations: OHBS-A, Arabic version of the Osteoporosis Health Belief Scale; OKT-A, Arabic version of Osteoporosis Knowledge Tool; OSES-A, Arabic version of Osteoporosis Self-Efficacy Scale.

The results showed moderate perceived susceptibility and seriousness for OP. In addition, there were positive correlations between perceived susceptibility and OKT-A and OSES-A total scores, while perceived seriousness was positively correlated with the OKT-A total score. These are important results given that the participants consider themselves susceptible, and it is a serious matter to get OP. Moreover, enhancing OP knowledge of participants will increase their belief toward susceptibility and seriousness of the disease and consequently enhance the changes in the prevention behavior toward the disease. . $^{42,43}$

The OKT-A and OSES-A exercise subscales were positively correlated to the perceived benefit of exercise. Therefore, more attention should be paid to that population and an educational program focusing on the benefit of exercise should be implemented to increase their awareness regarding exercise. The benefits of regular exercise are that it not only increases bone strength but also improves mood and physiological function, reduces the frequency of disease, and increases the quality of life. ${ }^{44-48}$ Moreover, perceived benefit of calcium showed same correlation with OKT-A

Table 6 Multivariate regression analysis summary

\begin{tabular}{lllll}
\hline Variables included & B (SE) & \multicolumn{3}{l}{$\mathbf{9 5 \% ~ C l}$ for odds ratio } \\
\cline { 3 - 6 } & & Lower & $\begin{array}{c}\text { Odds } \\
\text { ratio }\end{array}$ & Upper \\
\hline Constant & $-0.847(0.194)$ & & & \\
Age (categorical) & $-0.525(0.265)^{*}$ & 0.352 & 0.592 & 0.995 \\
OKT-A (categorical) & $0.916(0.269)^{* *}$ & 1.475 & 2.499 & 4.235 \\
OSES-A (categorical) & $0.881(0.336)^{* *}$ & 1.249 & 2.413 & 4.661 \\
\hline
\end{tabular}

Notes: $R^{2}=0.208$ (Hosmer-Lemeshow), 0.097 (Cox and Snell), and 0.133 (Nagelkerke). Model: $\chi^{2}(3)=30.676, P<0.001$. $* P<0.05$. $* * P<0.01$.

Abbreviations: OKT-A, Arabic version of Osteoporosis Knowledge Tool; OSES-A, Arabic version of Osteoporosis Self-Efficacy Scale; SE, standard error. 
and OSES-A calcium subscales. The calcium-rich foods not only improve bone health but also improve weight lost, decrease the incidence of metabolic syndrome, and decrease blood pressure. ${ }^{49-53}$

Furthermore, the OKT-A and OSES-A exercise and calcium subscales were positively correlated to the perceived barriers of exercise and calcium, respectively. These results revealed that more barriers were encountering the participants to be engaged in OP-preventive behaviors, although they were more aware about OP. The data showed insignificant differences between demographic data and barrier scales (results not shown). These results may be owing to the culture point of view and could be explained as follows: the highest frequencies (agree and strongly agree) were observed in exercise barrier questions "You feel like you are not strong enough to exercise regularly" and "You have no place where you can exercise". These revealed higher perceived difficulties, and the respondents did not know how to cope with these barriers. In Iraq, there are no free public gym centers and running in the streets is not acceptable culturally, and women engaging in outdoor exercises are not culturally acceptable also. Another study showed that inconvenience, cost, and time were the barriers responsible for not engaging in exercise. ${ }^{54}$ For calcium barrier subscale, the highest frequencies (agree and strongly agree) were observed for "Calcium rich foods cost too much" (54\%) and "You do not like calcium rich foods" (47\%), while that for the question "Calcium rich foods have too much cholesterol," it was $41.6 \%$. This implies that the educational program should focus on increasing the participants' knowledge regarding healthy calcium food intake and inexpensive alternatives. Similar results regarding calcium and exercise barriers were reported. ${ }^{19}$ In addition, the participants should know that there was no association between dairy products and metabolic disorders. . $^{53,55,56}$

Besides that, educators must emphasize on adequate calcium intake during adolescent age, when the peak bone density develops. ${ }^{57}$ Moreover, the results showed that the sample population still showed high perceived benefit to exercise and calcium belief percentage than the barrier, which is consistent with a previous report. ${ }^{58}$ Regarding health motivation scale, the respondents showed an excellent belief percentage with a positive correlation with knowledge subscales. This revealed that the respondents were highly motivated to engage in healthy behaviors and were concerned about learning the health issue and how to cope with it. Similar results of high health motivation subscale were reported. ${ }^{19}$

\section{Study limitation}

As with other cross-sectional studies, the results cannot be generalized for the entire population. However, the full and comprehensive translation and validation with a good sample size would improve the impact of this study.

\section{Conclusion}

Given the cultural obstacles, an educational program for both genders and all age groups is an urgent issue and must be tailored according to cultural needs. Thus, knowledge, health belief, and finely engaging in healthy behaviors are warranted.

\section{Disclosure}

The author reports no conflicts of interest in this work.

\section{References}

1. Cosman F, De Beur S, LeBoff M, et al. Clinician's guide to prevention and treatment of osteoporosis. Osteoporos Int. 2014;25(10): 2359-2381.

2. Lypaczewski G, Lappe J, Stubby J. 'Mom \& me' and healthy bones: an innovative approach to teaching bone health. Orthop Nurs. 2002;21(2): $35-42$.

3. New SA. Bone health: the role of micronutrients. Br Med Bull. 1999; 55(3):619-633.

4. Watts NB, Lewiecki EM, Miller PD, Baim S. National osteoporosis foundation 2008 clinician's guide to prevention and treatment of osteoporosis and the world health organization fracture risk assessment tool (FRAX): what they mean to the bone densitometrist and bone technologist. J Clin Densitom. 2008;11(4):473-477.

5. Magee JA, Stuberg WA, Schmutte GT. Bone health knowledge, selfefficacy, and behaviors in adolescent females. Pediatr Phys Ther. 2008; 20(2):160-166.

6. Uusi-Rasi K, Sieva H, Pasanen M, Oja P, Vuori I. Association of physical activity and calcium intake with the maintenance of bone mass in premenopausal women. Osteoporos Int. 2002;13(3):211-217.

7. Abdulameer SA, Syed Sulaiman SA, Hassali MAA, Subramaniam K, Sahib MN. Osteoporosis and type 2 diabetes mellitus: what do we know, and what we can do? Patient Prefer Adherence. 2012;6:435.

8. Bohaty K, Rocole H, Wehling K, Waltman N. Testing the effectiveness of an educational intervention to increase dietary intake of calcium and vitamin D in young adult women. $J$ Am Acad Nurse Pract. 2008; 20(2):93-99.

9. Kim KK, Horan ML, Gendler P, Patel MK. Development and evaluation of the osteoporosis health belief scale. Res Nurs Health. 1991;14(2): $155-163$.

10. Painter JE, Borba CP, Hynes M, Mays D, Karen G. The use of theory in health behavior research from 2000 to 2005: a systematic review. Ann Behav Med. 2008;35(3):358-362.

11. Rosenstock IM. The health belief model and preventive health behavior. Health Educ Behav. 1974;2:354-386.

12. Giangregorio L, Fisher P, Papaioannou A, Adachi JD. Osteoporosis knowledge and information needs in healthcare professionals caring for patients with fragility fractures. Orthop Nurs. 2007;26(1):27-35.

13. Yeap SS, Goh EM, Gupta ED. Knowledge about osteoporosis in a Malaysian population. Asia Pac J Public Health. 2010;22(2):233-241.

14. Bandura A, Adams N. Analysis of self-efficacy theory of behavioral change. Cognit Ther Res. 1977;1:287-310.

15. Anderson KD, Chad KE, Spink KS. Osteoporosis knowledge, beliefs, and practices among adolescent females. J Adolesc Health. 2005;36(4): 305-312. 
16. Gurney S, Simmonds J. Osteoporosis: a teenage perspective. Physiotherapy. 2007;93:267-272.

17. Sedlak CA, Doheny MO, Jones SL. Osteoporosis education programs: changing knowledge and behaviors. Public Health Nurs. 2000;17(5):398-402.

18. von Hurst PR, Wham CA. Attitudes and knowledge about osteoporosis risk prevention: a survey of New Zealand women. Public Health Nutr. 2007;10(7):747-753.

19. Ford MA, Bass M, Zhao Y, Bai J-B, Zhao Y. Osteoporosis knowledge, self-efficacy, and beliefs among college students in the USA and China. J Osteoporos. 2011;2011:729219.

20. Kasper MJ, Peterson MG, Allegrante JP. The need for comprehensive educational osteoporosis prevention programs for young women: results from a second osteoporosis prevention survey. Arthritis Care Res. 2001;45(1):28-34.

21. Lee L, Lai E. Osteoporosis in older Chinese men: knowledge and health beliefs. J Clin Nurs. 2006;15(3):353-355.

22. Ozturk A, Sendir M. Evaluation of knowledge of osteoporosis and selfefficacy perception of female orthopaedic patients in Turkey. $J$ Nurs Healthc Chronic Illn. 2011;3:319-328.

23. Streiner DL, Norman GR, Cairney J. Health Measurement Scales: A Practical Guide to Their Development and Use. USA: Oxford University Press; 2015.

24. Field A. Discovering Statistics Using SPSS. London: SAGE; 2009.

25. Dawson-Saunders B, Trapp RG. Basic and Clinical Biostatistics. New York: Lange Medical Books/McGraw-Hill; 2004.

26. Kim K, Horan M, Gendler P. Osteoporosis Knowledge Tests, Osteoporosis Health Belief Scale, and Osteoporosis Self-Efficacy Scale. Allendale, MI: Grand Valley State University; 1991.

27. Abdulameer SA, Syed Sulaiman SA, Hassali MA, Sahib MN, Subramaniam K. Psychometric properties of the Malay version of the osteoporosis health belief scale (OHBS-M) among type 2 diabetic patients. Int J Rheum Dis. 2014;17(1):93-105.

28. Horan ML, Kim KK, Gendler P, Froman RD, Patel MD. Development and evaluation of the osteoporosis self-efficacy scale. Res Nurs Health. 1998;21(5):395-403.

29. Beaton DE, Bombardier C, Guillemin F, Ferraz MB. Guidelines for the process of cross-cultural adaptation of self-report measures. Spine. 2000;25(24):3186-3191.

30. Guillemin F, Bombardier C, Beaton D. Cross-cultural adaptation of health-related quality of life measures: literature review and proposed guidelines. J Clin Epidemiol. 1993;46(12):1417-1432.

31. Wild D, Grove A, Martin M, et al. Principles of good practice for the translation and cultural adaptation process for patient-reported outcomes (PRO) measures: report of the ISPOR task force for translation and cultural adaptation. Value Health. 2005;8(2):94-104.

32. DeVon HA, Block ME, Moyle-Wright P, et al. A psychometric toolbox for testing validity and reliability. J Nurs Scholarsh. 2007;39(2): $155-164$.

33. Fabrigar LR, Wegener DT, MacCallum RC, Strahan EJ. Evaluating the use of exploratory factor analysis in psychological research. Psychol Methods. 1999;4:272.

34. Cronbach LJ. Coefficient alpha and the internal structure of tests. Psychometrika. 1951;16:297-334.

35. Bartlett MS. Tests of significance in factor analysis. Br J Math Stat Psychol. 1950;3:77-85.

36. Bartlett MS. A further note on tests of significance in factor analysis. Br J Math Stat Psychol. 1951;4:1-2.

37. Baheiraei A, Ritchie JE, Eisman JA, Nguyen TV. Psychometric properties of the Persian version of the osteoporosis knowledge and health belief questionnaires. Maturitas. 2005;50(2):134-139.

38. Geller SE, Derman R. Knowledge, beliefs, and risk factors for osteoporosis among African-American and Hispanic women. J Natl Med Assoc. 2001;93(1):13.
39. Saw S-M, Hong C-Y, Lee J, et al. Awareness and health beliefs of women towards osteoporosis. Osteoporos Int. 2003;14(7):595-601.

40. Nayak S, Roberts MS, Chang C-CH, Greenspan SL. Health beliefs about osteoporosis and osteoporosis screening in older women and men. Health Educ J. 2010;69(3):267-276.

41. Jalili Z, Nakhaee N, Askari R, Sharifi V. Knowledge, attitude and preventive practice of women concerning osteoporosis. Iran J Public Health. 2007;36:19-25.

42. Janz NK, Becker MH. The health belief model: a decade later. Health Educ Q. 1984;11(1):1-47.

43. Piaseu N, Belza B, Mitchell P. Testing the effectiveness of an osteoporosis educational program for nursing students in Thailand. Arthritis Care Res. 2001;45(3):246-251.

44. Bize R, Johnson JA, Plotnikoff RC. Physical activity level and healthrelated quality of life in the general adult population: a systematic review. Prev Med. 2007;45(6):401-415.

45. De Moor MH, Beem AL, Stubbe JH, Boomsma DI, De Geus EJ. Regular exercise, anxiety, depression and personality: a population-based study. Prev Med. 2006;42(4):273-279.

46. Kokkinos PF, Narayan P, Colleran JA, et al. Effects of regular exercise on blood pressure and left ventricular hypertrophy in AfricanAmerican men with severe hypertension. NEngl J Med. 1995;333(22): $1462-1467$.

47. Kraus WE, Slentz CA. Exercise training, lipid regulation, and insulin action: a tangled web of cause and effect. Obesity. 2009;17(suppl 3): S21-S26.

48. Radak Z, Chung HY, Koltai E, Taylor AW, Goto S. Exercise, oxidative stress and hormesis. Ageing Res Rev. 2008;7(1):34-42.

49. Ascherio A, Hennekens C, Willett WC, et al. Prospective study of nutritional factors, blood pressure, and hypertension among US women. Hypertension. 1996;27(5):1065-1072.

50. Azadbakht L, Mirmiran P, Esmaillzadeh A, Azizi F. Dairy consumption is inversely associated with the prevalence of the metabolic syndrome in Tehranian adults. Am J Clin Nutr. 2005;82(3):523-530.

51. Davies KM, Heaney RP, Recker RR, et al. Calcium intake and body weight. J Clin Endocrinol Metab. 2000;85(12):4635-4638.

52. Mirmiran P, Esmaillzadeh A, Azizi F. Dairy consumption and body mass index: an inverse relationship. Int J Obes. 2005;29(1):115.

53. Pereira MA, Jacobs DR Jr, Van Horn L, Slattery ML, Kartashov AI, Ludwig DS. Dairy consumption, obesity, and the insulin resistance syndrome in young adults: the CARDIA study. JAMA. 2002;287(16): 2081-2089.

54. Sedlak CA, Doheny MO, Jones SL. Osteoporosis prevention in young women. Orthop Nurs. 1998;17(3):53.

55. Beydoun MA, Gary TL, Caballero BH, Lawrence RS, Cheskin LJ, Wang Y. Ethnic differences in dairy and related nutrient consumption among US adults and their association with obesity, central obesity, and the metabolic syndrome. Am J Clin Nutr. 2008;87(6): 1914-1925.

56. Phillips S, Bandini L, Cyr H, Colclough-Douglas S, Naumova E, Must A. Dairy food consumption and body weight and fatness studied longitudinally over the adolescent period. Int J Obes. 2003; 27(9):1106.

57. Bronner YL, Hawkins AS, Holt ML, et al. Models for nutrition education to increase consumption of calcium and dairy products among African Americans. J Nutr. 2006;136(4):1103-1106.

58. Endicott RD. Knowledge, health beliefs, and self-efficacy regarding osteoporosis in perimenopausal women. J Osteoporos. 2013;2013: 853531 . 
Patient Preference and Adherence

Dovepress

\section{Publish your work in this journal}

Patient Preference and Adherence is an international, peer-reviewed, open access journal that focuses on the growing importance of patient preference and adherence throughout the therapeutic continuum. Patient satisfaction, acceptability, quality of life, compliance, persistence and their role in developing new therapeutic modalities and compounds to optimize

clinical outcomes for existing disease states are major areas of interest for the journal. This journal has been accepted for indexing on PubMed Central. The manuscript management system is completely online and includes a very quick and fair peer-review system, which is all easy to use. Visit http://www. dovepress.com/testimonials.php to read real quotes from published authors.

Submit your manuscript here: http://www.dovepress.com/patient-preference-and-adherence-journal 